\title{
Influence of celecoxib on the vasodilating properties of human mesenteric arteries constricted with endothelin-1
}

\author{
GRZEGORZ GRZEŚK* , KATARZYNA SZADUJKIS-SZADURSKA*, GRZEGORZ MATUSIAK, \\ BARTOSZ MALINOWSKI, MARTA GAJDUS, MICHAŁ WICIŃSKI and LESZEK SZADUJKIS-SZADURSKI
}

\author{
Department of Pharmacology and Therapeutics, Collegium Medicum, \\ Nicolaus Copernicus University, Bydgoszcz 85-094, Poland
}

Received November 22, 2013; Accepted January 10, 2014

DOI: $10.3892 /$ br.2014.233

\begin{abstract}
The mitogenic and vasoconstrictive properties of the vascular system are attributed to endothelin-1 (ET-1). ET-1 serum concentration increases in a number of pathological conditions, particularly in those associated with blood vessel constriction. ET-1 is also associated with the underlying pathomechanisms of primary pulmonary hypertension, arterial hypertension and eclampsia. The aim of this study was to compare the vasodilating properties of selected phosphodiesterase (PDE) inhibitors and celecoxib in human mesenteric arteries constricted with ET-1, and investigate the role of the endothelium in relaxation. Perfused human mesenteric arteries were collected and stored under the same conditions as organs for transplantation. The mesenteric arteries (with and without the endothelium) were constricted by the addition of ET-1 and treated with one of the following: sildenafil (PDE5 inhibitor), zaprinast (PDE5 and 6 inhibitor), rolipram (PDE4 inhibitor) and celecoxib [cyclooxygenase-2 (COX-2) inhibitor]. Based on the observed changes of the perfusion pressure, concentration response curves (CRCs) were prepared for the respective inhibitors and the $\mathrm{EC}_{50}$ (concentration causing an effect equal to half of the maximum effect), $\mathrm{pD}_{2}$ (negative common logarithm of $\mathrm{EC}_{50}$ ) and relative potency (RP) were calculated. The results suggested that all the inhibitors triggered a concentration-dependent decrease in the perfusion pressure in isolated human superior mesenteric arteries with endothelium constricted by the addition of ET-1. In the arteries without endothelium, CRCs for celecoxib and rolipram were shifted to the right without a significant decrease in the maximum dilating effect. Moreover, CRCs for sildenafil and zaprinast were
\end{abstract}

Correspondence to: Professor Grzegorz Grześk, Department of Pharmacology and Therapeutics, Collegium Medicum, Nicolaus Copernicus University, 9 Marii Skłodowskiej-Curie, Bydgoszcz 85-094, Poland

E-mail: ggrzesk@cm.umk.pl

*Contributed equally

Key words: endothelin-1, celecoxib, phosphodiesterase inhibitors, constriction, endothelium shifted to the right with a simultaneous significant decrease in the maximum dilating effect and with an increased inclination angle in reference to the concentration axis. In the presence of the endothelium, all of the evaluated PDE inhibitors, as well as celecoxib, reduced the reactivity of the mesenteric arteries caused by ET-1. Sildenafil indicated the lowest efficacy in the presence of the endothelium, but showed a higher potency compared to that of the other compounds. Removing the endothelium significantly reduced the vasodilating efficacy of PDE5 and 6 inhibitors and a statistically significant influence on the vasodilating efficacy of PDE4 inhibitor and celecoxib was observed. The high vasorelaxing efficacy of celecoxib at the background of the PDE inhibitors was observed, not only in the presence, but also in the absence of the endothelium and may be evidence for the relaxation induced by this COX-2 inhibitor in the cAMP- and cGMP-dependent pathways.

\section{Introduction}

Due to numerous enzymes and receptors, the endothelium is an active platform for the interaction between blood (including signaling substances carried in the blood) and the vessel wall, playing a fundamental role in regulating vasomotor activity, hemostasis and angiogenesis, as well as in controlling inflammatory and immune processes. Key characteristics allowing the endothelium to perform these functions include speed in the stimulation of its cells and their response to stimuli.

Efficient vasoconstriction and vasodilatation, as well as the resulting influence on the arterial pressure and blood supply to tissues depend on a number of substances secreted by the endothelium in response to stimulation by shear stress, hypoxia and acetylcholine, bradykinin or serotonin action. Vasoactive substances of endothelial origin include the group with vasoconstrictive properties [such as endothelin, angiotensin II, platelet-activating factor, thromboxane $\mathrm{A}_{2}\left(\mathrm{TXA}_{2}\right)$, leukotriene $\mathrm{A}_{4}$ and $\mathrm{B}_{4}, \mathrm{ATP}$ and $\left.\mathrm{ADP}\right]$ and the group, which stimulates dilation of the vessels [such as nitric oxide (NO), prostacyclin $\left(\mathrm{PGI}_{2}\right)$, vasodilator-stimulated phosphoprotein, endothelium-derived hyperpolarizing factor and adenosine as a product of the membranous ectonucleases degrading ATP and ADP] (1). Due to secretion of NO, the endothelium is also responsible for paracrine antioxidative action (limiting oxidation of low-density lipoproteins on the subendothelial 
space) and antiproliferative action (inhibiting mitogenesis of the smooth muscle cells). PGI $_{2}$ diffusing into the vessel lumen determines the antiaggregant action of the endothelium on the platelets.

Mitogenic and vasoconstrictive properties are attributed to endothelin-1 (ET-1) in the vascular system. The serum concentrations of ET-1 increase in a number of pathological conditions, particularly in those associated with blood vessel constriction. ET-1 is also associated with the underlying pathomechanisms of primary pulmonary hypertension, arterial hypertension and eclampsia.

Cyclooxygenase (prostaglandin $\mathrm{G} / \mathrm{H}$ synthase) is an enzyme transforming arachidonic acid to cyclic peroxides (prostaglandin $\mathrm{G}_{2}$ and $\mathrm{H}_{2}$ ), which are unstable reaction intermediates and precursors of $\mathrm{TXA}_{2}, \mathrm{PGI}_{2}$ and other prostaglandins $\left(\mathrm{PGE}_{2}, \mathrm{PGF}_{2}\right.$ and $\left.\mathrm{PGD}_{2}\right)$. Two forms of cyclooxygenase were isolated, cyclooxygenase-1 (COX-1) and COX-2. COX-1 is mainly a constitutive isoform, which is present in the majority of cells and tissues; however, certain cytokines, growth factors, mitogens, ischemia and several other chemical and physical damaging factors induce COX-2 synthesis. COX-1 may maintain functions, such as cytoprotection of the gastric epithelium and COX-2 is the main source of prostanoids during inflammation or the development of neoplasms. However, in certain tissues, COX-2 is also a constitutive enzyme (in the brain and kidney tissues) and is produced in the endothelium as a result of laminar friction force constituting a crucial link in the process of vascular tone adaptation. Therefore, the assumption that COX-2 is the enzyme independently responsible for inflammatory processes currently appears to be incorrect. Previous studies on COX-2 knockout mice reported that COX-1 was able to produce a sufficient amount of prostaglandins to induce a full inflammatory response (2). In the heterological system of expression, COX-1 preferentially binds with $\mathrm{TXA}_{2}$ synthase and $\mathrm{PGF}_{2}$ synthase, whereas COX-2 preferentially binds with $\mathrm{PGI}_{2}$ synthase (3).

All eicosanoid receptors belong to a group of receptors bound to $\mathrm{G}$ protein known as $\mathrm{G}$ protein-coupled receptors (GPCRs). Activation of GPCRs results in the modulation of adenylyl cyclase and phospholipase $\mathrm{C}$ activity due to the well-documented role of cyclooxygenases in inflammatory processes, amplification processes of pain sensations and in body temperature regulation. These enzymes are an attractive target for pharmacological symptomatic treatment. Non-steroidal anti-inflammatory drugs (NSAIDs), acetylsalicylic acid and acetaminophen interact with COX-1 and COX-2.

The hypothesis that anti-inflammatory effects may be separated from an ulcerogenic effect encouraged investigators to assess agents with a higher selectivity to COX-2 than to COX-1. A group of compounds referred to as coxibs, which currently include celecoxib, rofecoxib, etoricoxib, valdecoxib, lumiracoxib and several others were identified. Further studies reported that their selectivity with regards to $\mathrm{COX}-2$ is similar to the selectivity of previously identified NSAIDs, such as meloxicam, nimesulide and diclofenac. In vivo, selective COX-2 inhibitors reduce the production of $\mathrm{PGI}_{2}$ by endothelial cells without simultaneous inhibition of the platelet thromboxane. Thus, selective COX-2 inhibitors may increase the risk of a thrombus (4-7). Furthermore, animal studies conducted on mice and extensive epidemiological data suggest that the probability of the occurrence of hypertension caused by NSAIDs reflects a degree of COX-2 inhibition and selectivity of this process. Constitutive activity of COX-2 was reported in the vascular endothelial cells in patients with sclerosis or diabetes mellitus (2) and increased concerns as regards the safety of using this group of agents in humans (8).

Celecoxib, which has an affinity to COX-2 that is $\sim 375$-fold higher compared to its affinity to COX-1, was registered for the symptomatic treatment of inflammation and pain in patients with osteoarthritis, rheumatoid arthritis and ankylosing spondylitis. It is also used to reduce the number of adenomatous polyps in patients with familial adenomatous polyposis, as a therapy for supporting surgical treatment and for further endoscopic control (9).

The number of available studies on the role of celecoxib in modulating receptors of intracellular signaling pathways, which eliminate endothelin-dependant vascular constriction, is currently limited. The present study compared celecoxib and substances with known vasodilating properties (considering the dependence of these properties on the presence of the endothelium) in a series of experiments on mesenteric arteries using ET-1 to induce vascular constriction.

Investigating the methods for antagonizing constrictive properties of endothelin by modifying intracellular signaling pathways of the vascular smooth muscles and studying their dependence on paracrine activity of the endothelium may contribute to more effective treatment of the aforementioned diseases and aid in the search for novel methods to prevent their complications.

This study aimed to compare the vasodilating properties of selected phosphodiesterase (PDE) inhibitors and celecoxib in human mesenteric arteries constricted with ET-1, as well as investigate the role of the endothelium in relaxation.

\section{Materials and methods}

Materials and reagents. Human mesenteric arteries were obtained from subjects whose organs were collected for transplantation and stored under the same conditions. Human superior mesenteric arteries were collected in compliance with binding legal regulations. The Bioethics Committee at the Collegium Medicum, Nicolaus Copernicus University (Bydgoszcz, Poland) provided consent for conducting this experiment (KB/344/2005 and KB/252/2008). The patient or the patients' family gave informed consent. All the reagents used in this study were purchased from Sigma-Aldrich (Poznan, Poland).

Treatment of perfused human mesenteric arteries with endothelium. In the first series of experiments, the mesenteric arteries with a maintained endothelium, constricted by the addition of ET- $1\left(6.5 \times 10^{-9} \mathrm{~mol} / \mathrm{L}\right)$ were treated with increased concentrations of the following: sildenafil (PDE5 inhibitor; $0.1 \times 10^{-9}$ to $1 \times 10^{-6} \mathrm{M}$ ), zaprinast (PDE5 and 6 inhibitor; $3 \times 10^{-8}$ to $3 \times 10^{-4} \mathrm{M}$ ), rolipram (PDE4 inhibitor; $3 \times 10^{-7}$ to $3 \times 10^{-3} \mathrm{M}$ ) and celecoxib (COX-2 inhibitor; $3 \times 10^{-9}$ to $3 \times 10^{-5} \mathrm{M}$ ). Based on the observed changes in perfusion pressure, concentration response curves (CRCs) were prepared for the respective inhibitors and the following were calculated: $\mathrm{EC}_{50}$ (concentration causing an effect equal to half 


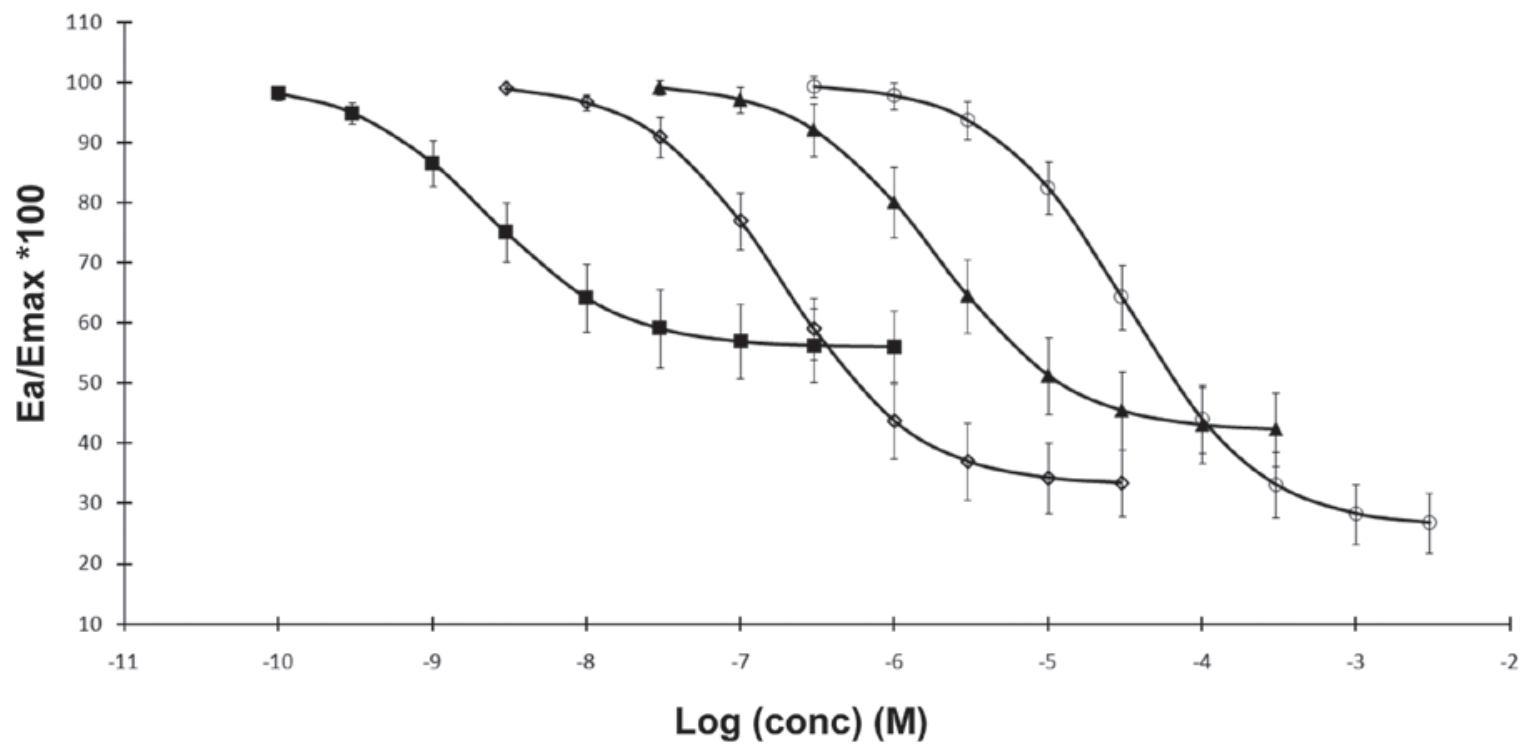

$\rightarrow$ Celecoxib with endothelium $\rightarrow$ - Sildenafil with endothelium
- Zaprinast with endothelium $\bullet$ Rolipram with endothelium

Figure 1. CRCs for celecoxib, zaprinast, sildenaphil and rolipram. The study was performed on human mesenteric arteries (with endothelium) contracted by ET-1. All the inhibitors triggered a concentration-dependent decrease in perfusion pressure in the mesenteric arteries. Points marked on the CRC present the mean relaxation effect in $\%$ and $\mathrm{SE}$ ( $\mathrm{n}=12$ arteries per group). Graphs were approximated to sigmoidal curve. CRC, concentration response curves; ET-1, endothelin-1; SE, standard error; Emax, maximal response produced by the drug.

of the maximum effect), $\mathrm{pD}_{2}$ (negative common logarithm of $\mathrm{EC}_{50}$ value) and relative potency (RP), i.e., quotient of $\mathrm{EC}_{50}$ control value and $\mathrm{EC}_{50}$ value analyzed in the experimental systems. This series of experiments facilitated the comparison of the efficacy of selected PDE inhibitors and celecoxib in the dilation of mesenteric arteries.

Treatment of perfused human mesenteric arteries without endothelium. The next series of experiments were conducted in a manner similar to the aforementioned one; however, prior to the experiment, the endothelium was removed from the vessels using compressed air in accordance with the methodology developed by Koller et al (10). Precision of endothelium removal was verified using a perfusate containing acetylcholine chloride in a concentration of $1 \times 10^{-5} \mathrm{M}$. The occurrence of constriction of the vessel was recognized as confirmation that the endothelium was absent. This series of experiments facilitated the comparative evaluation of the efficacy of selected PDE inhibitors and celecoxib in the dilation of mesenteric arteries and the influence of the endothelium.

Statistical analysis. Statistical analysis was performed by calculating the mean values and standard deviations. The results are presented as the means of serial measurements with consideration of the standard error of the mean. $\mathrm{P}<0.05$ was considered to indicate a statistically significant difference. Values of $0.05 \leq \mathrm{P}<0.1$ expressed a trend towards statistical significance, but values of $\mathrm{P} \geq 0.1$ were not significant.

\section{Results}

PDE inhibitors and celecoxib decreased the perfusion pressure in human mesenteric arteries with endothelium.
The series of experiments conducted on perfused human mesenteric arteries with a maintained endothelium revealed that all the PDE inhibitors and celecoxib triggered a concentration-dependent decrease in perfusion pressure in isolated arteries constricted by ET-1 (Fig. 1). The PDE inhibitors and COX-2 inhibitor indicated characteristics of non-competitive (functional) antagonists and did not completely eliminate vascular constriction caused by ET-1 (Fig. 3). The basic pharmacometric parameters of human mesenteric arteries (with and without endothelium) treated with PDE inhibitors and celecoxib and constricted by ET-1 are summarized in Table I.

Analysis of PDE inhibitors and celecoxib in human mesenteric arteries without endothelium. The series of experiments conducted on the arteries with removed endothelium showed that CRCs for celecoxib and rolipram were shifted to the right without a statistically significant decrease in the maximum dilating effect of celecoxib and the PDE4 inhibitor (Fig. 2). Furthermore, CRCs for sildenafil and zaprinast were shifted to the right, but with a simultaneous statistically significant decrease in the maximum dilating effect of PDE5 and PDE5/6 inhibitors and with an increased inclination angle in reference to the concentration axis (Fig. 2). The PDE inhibitors and COX-2 inhibitor demonstrated characteristics of non-competitive (functional) antagonists in vessels without an endothelium and did not completely eliminate vascular constriction caused by ET-1.

Comparative analysis of CRCs for PDE inhibitors and celecoxib in human mesenteric arteries with and without endothelium. Comparative analysis of the CRCs for the PDE inhibitors and the COX-2 inhibitor in mesenteric arteries with and without the endothelium suggested that removal of the 
Table I. Pharmacometric parameters of human mesenteric arteries (with and without endothelium) treated with PDE inhibitors or celecoxib and constricted by ET-1.

\begin{tabular}{|c|c|c|c|c|c|c|c|c|c|c|}
\hline Treatments & No. & $\begin{array}{l}\mathrm{EC}_{50} \\
(\mathrm{M} / \mathrm{L})\end{array}$ & $\begin{array}{c}\mathrm{SE} \\
\left(\mathrm{EC}_{50}\right)\end{array}$ & $\begin{array}{c}\text { P-value } \\
\left(\mathrm{EC}_{50}\right)\end{array}$ & $\mathrm{pD}_{2}$ & $\begin{array}{l}\mathrm{Em} \\
(\%)\end{array}$ & $\begin{array}{c}\mathrm{SE} \\
(\mathrm{Em} \%)\end{array}$ & $\begin{array}{l}\text { P-value } \\
(\text { Em) }\end{array}$ & $\begin{array}{l}\mathrm{RP} 1 \\
(\%)\end{array}$ & $\begin{array}{l}\mathrm{RP} 2 \\
(\%)\end{array}$ \\
\hline \multicolumn{11}{|c|}{$\begin{array}{l}\text { Mesenteric arteries } \\
\text { with endothelium }\end{array}$} \\
\hline Celecoxib & 12 & $1.91 \mathrm{E}-07$ & $0.08 \mathrm{E}-07$ & - & -6.72 & 67 & 5.6 & - & 1.7 & 0.45 \\
\hline Sildenafil & 12 & 2.29E-09 & 0.04E-09 & - & -8.64 & 44 & 6.3 & - & 138.4 & 1.35 \\
\hline Zaprinast & 12 & $1.91 \mathrm{E}-06$ & $0.05 \mathrm{E}-06$ & - & -5.72 & 58 & 4.9 & - & 0.2 & 7.24 \\
\hline $\begin{array}{l}\text { Rolipram } \\
\text { without enc }\end{array}$ & 12 & $3.22 \mathrm{E}-05$ & $0.04 \mathrm{E}-05$ & - & -4.49 & 74 & 6.1 & - & 0.01 & 44.91 \\
\hline Celecoxib & 12 & $4.27 \mathrm{E}-05$ & $0.04 \mathrm{E}-05$ & $<0.001$ & -4.37 & 64 & 6.1 & NS & 0.01 & 0.45 \\
\hline Sildenafil & 12 & $1.70 \mathrm{E}-07$ & $0.07 \mathrm{E}-07$ & $<0.001$ & -6.77 & 22 & 4.6 & $<0.001$ & 1.9 & 1.35 \\
\hline Zaprinast & 12 & $2.63 \mathrm{E}-05$ & $0.04 \mathrm{E}-05$ & $<0.001$ & -4.58 & 18 & 4.4 & $<0.001$ & 0.01 & 7.24 \\
\hline Rolipram & 12 & 7.17E-05 & $0.06 \mathrm{E}-05$ & $<0.001$ & -4.14 & 69 & 5.8 & 0.052 & 0.00 & 44.91 \\
\hline
\end{tabular}

Human mesenteric artery smooth muscle cells were treated with increasing concentrations of celecoxib, sildenafil, rolipram and zaprinast, for normal and endothelium-denudated arteries. PDE, phosphodiesterase; ET-1, endothelin-1; $\mathrm{EC}_{50}$, concentration causing an effect equal to half of the maximum effect; $\mathrm{SE}$, standard error of the mean; $\mathrm{pD}_{2}$, negative common logarithm of $\mathrm{EC}_{50} ; \mathrm{Em}$, maximum effect; $\mathrm{NS}$, no significance; $\mathrm{RP}$, relative potency. RP1 with endothelium was calculated using the assumed control (reference) value of $\mathrm{EC}_{50} \mathrm{ET}^{-1}$ and referred value, $\mathrm{EC}_{50}$ of an analyzed substance in the system with the endothelium. RP1 without endothelium was calculated as aforementioned, but in mesenteric arteries without endothelium. RP2 was calculated using the assumed control (reference) value of $\mathrm{EC}_{50}$ of an analyzed substance in the system with the endothelium and referred value, $\mathrm{EC}_{50}$ of an analyzed substance in the system without the endothelium.

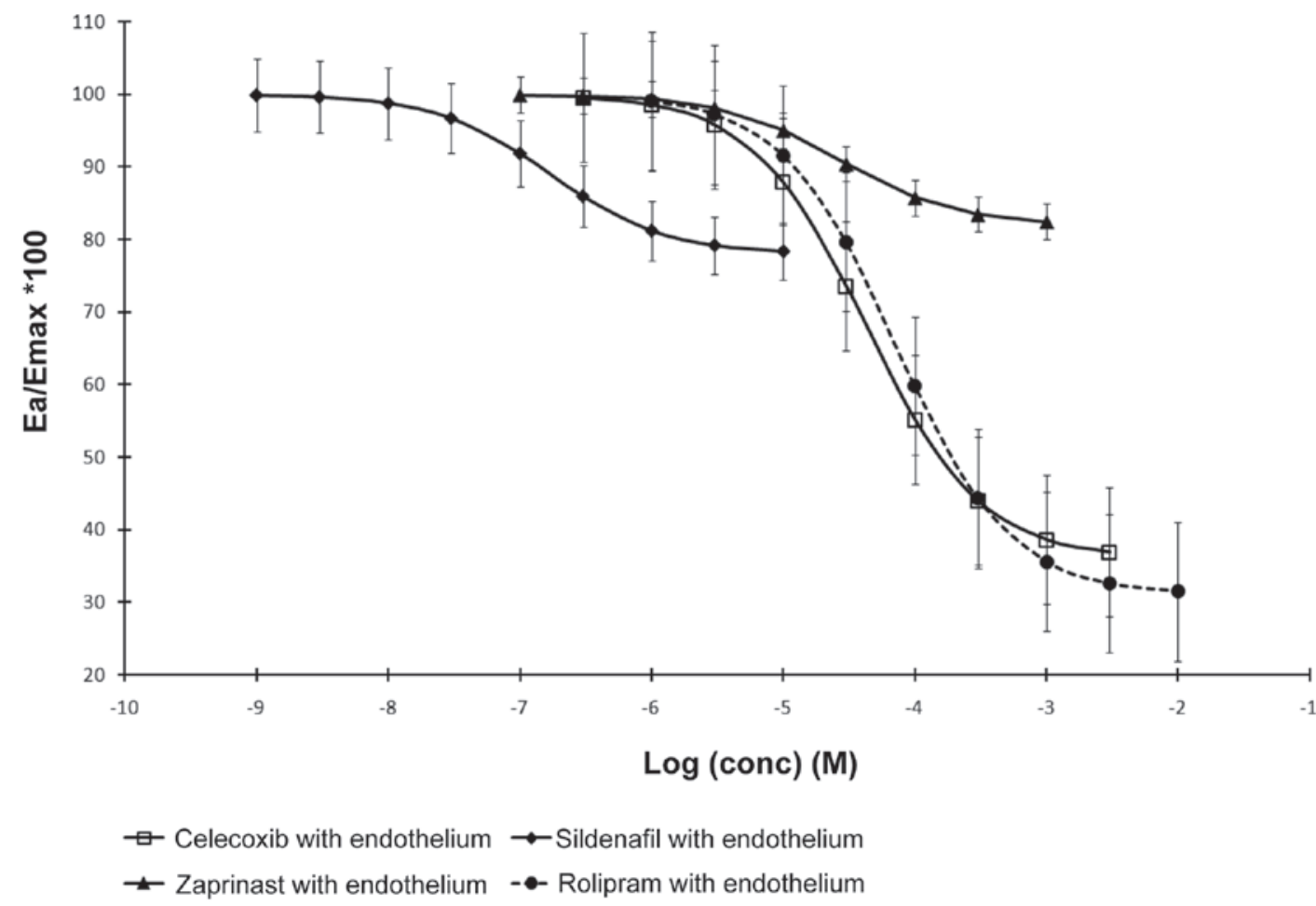

Figure 2. CRCs for celecoxib, zaprinast, sildenafil and rolipram. The study was performed on human mesenteric arteries (without endothelium) contracted by ET-1. Points marked on the CRC present the mean relaxation effect in \% and SE ( $\mathrm{n}=12$ arteries per group). Graphs were approximated to the sigmoidal curve. CRCs, concentration response curves; ET-1, endothelium; SE, standard error.

endothelium corresponds to a model of competitive inhibition in reference to the vasodilating effects of celecoxib and rolipram and non-competitive inhibition in reference to the vasodilating effects of zaprinast and sildenafil.

\section{Discussion}

A recognized method for limiting the use of vasodilative factors is inhibiting the decomposition of cyclic monoribonucleotides, 


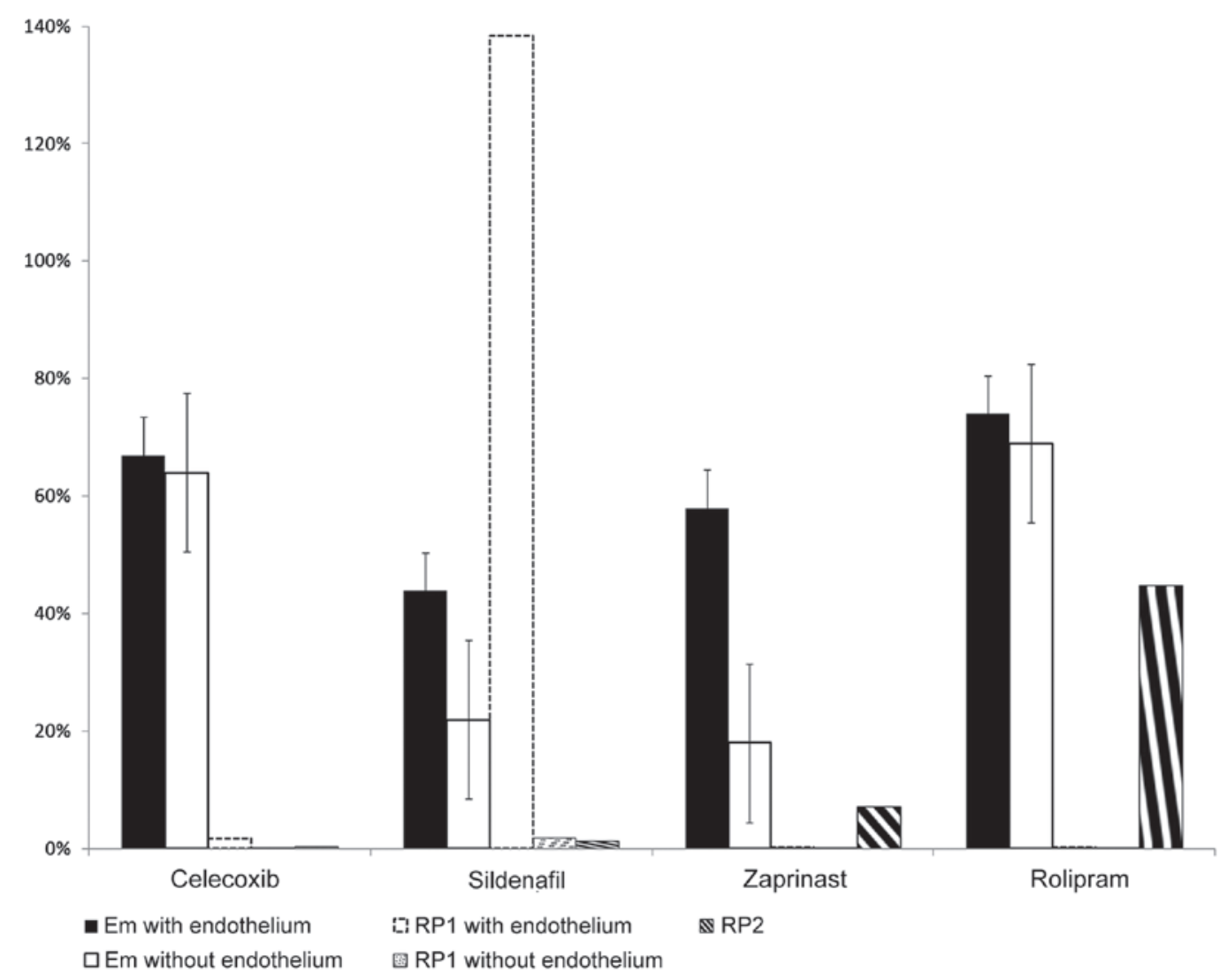

Figure 3. Em and RP of celecoxib, sildenafil, rolipram and zaprinast for human mesenteric arteries, with and without the endothelium constricted by ET-1. Results are based on the data from Table I. Em, maximum effect; RP, relative potency.

cAMP and cGMP. Cyclic nucleotides, cAMP and cGMP, are synthesized intracellularly by adenylyl and guanylyl cyclases (11-13) in the presence of $\mathrm{Mg}^{2+}$ ions. They activate protein kinases, PKA and PKG, regulate the intracellular $\mathrm{Ca}^{2+}$ concentration and influence the function of ion channels (14-16). An increased level of cyclic nucleotides results in a decreased concentration of cytoplasmic $\mathrm{Ca}^{2+}$, decreased sensitivity of the smooth muscles to calcium and consequently leads to dilation $(17,18)$.

The concentration of cGMP in vascular smooth muscle cells is associated with the condition of the endothelium. A stimulated endothelium produces NO, which diffuses into the muscular layer and stimulates cGMP production by covalently binding to a heme group of soluble guanylyl cyclases (sGC) $(19,20)$. It has been reported that aquaporin-1 transports NO through the cell membranes (21) and the synthesis of aquaporins is inhibited by ET-1 (22). However, Slupski et al (23) reported that sodium pump stimulation by $\mathrm{YC}-1$, as an additional mechanism of sGC activation independent of cGMP, relaxed human mesenteric arteries, including blockade of calcium ion influx.

The influence of the endothelium on reserves of cAMP is much less explicit. Although locally produced $\mathrm{PGE}_{2}$ and $\mathrm{PGI}_{2}$ reduce the tone of the blood vessel walls by GPCRs (IP and $\mathrm{EP})$, the endothelium is also recognized as a potential source of $\mathrm{PGH}_{2}$, a vasoconstricting prostanoid, which acts by reducing the concentration of cAMP in the smooth muscle cells. PGI, the main metabolite of the arachidonic acid released from the vascular endothelium, is mainly produced in humans with the participation of COX-2 (24). $\mathrm{PGH}_{2}$ synthesis is controlled by shear stress and autacoids, which constrict and dilate vessels. A previous study suggested that the role of $\mathrm{PGI}_{2}$ in the local regulation of vascular tone was not significant, but studies analyzing the polymorphism of $\mathrm{PGI}_{2}$ found an association between the risk of myocardial infarction and severe hypertension (3). Simultaneously, it was reported that $\mathrm{PGI}_{2}$ limits pulmonary hypertension induced by hypoxia and general hypertension caused by angiotensin II (25). $\mathrm{PGE}_{2}$, produced in the endothelium with the participation of COX-2 and through the $\mathrm{EP}_{4}$ receptor, maintains the patent arterial duct until birth, when decreased levels of $\mathrm{PGE}_{2}$ result in its closing (26). Discrepant observations in the case of $\mathrm{PGE}_{2}$ may result from the multitude of receptors for this prostanoid.

The present study compared celecoxib, a COX-2 inhibitor with unique properties of inhibiting PDE5 and 4, with classical PDE inhibitors occurring in the endothelium (PDE4, 5 and 6). Our results suggested that superior mesenteric arteries with a maintained endothelium and constricted with ET-1 responded to the vasodilative action of all the PDE inhibitors as well as celecoxib. With regards to sildenafil, a reduced perfusion pressure by $\sim 44 \%$ of the maximum effect of ET-1 was achieved. Zaprinast and rolipram were found to be more effective in causing dilation. In the mesenteric arteries with a maintained endothelium, celecoxib triggered a concentration-dependent reduction in perfusion pressure reaching $67 \%$ of the maximum effects of ET-1 and this result did not statistically differ from those of rolipram and zaprinast. Sildenafil showed the lowest $\mathrm{EC}_{50}$ value of $2.29( \pm 0.04) \times 10^{-9} \mathrm{M} / \mathrm{L}$. In addition, low 
concentrations of PDE inhibitors, celecoxib and other studied substances were not able to reach dilation efficacy, which was equal to the efficacy of sildenafil.

The reduced myorelaxing efficacy of the PDE5 and 6 inhibitors was notable while comparing the results obtained in arteries with endothelium and those without endothelium. Our results suggested that cAMP plays a crucial role in vasoreactivity of the choke vessels, but it is mainly independent from the endothelium. Celecoxib is a poor PDE4 inhibitor and showed its ability to increase cAMP at high concentrations; however, at lower concentrations it efficiently acts through PDE5 inhibition. Thus, vasorelaxant pathways based on cGMP may be referred to as the pathways controlled by the presence and condition of the endothelium, and vasorelaxant pathways based on cAMP may be referred to as the endothelium-independent pathways.

The vascular effects of celecoxib have been approached carefully. Data provided by two large, randomized and double-blinded clinical studies with the use of celecoxib (Celecoxib Long-term Arthritis Safety Study) and rofecoxib [Vioxx ${ }^{\circledR}$ Gastrointestinal Outcomes Research (VIGOR)] in patients with chronic arthritis, despite the fact that fewer adverse events associated with an alimentary tract in the group of patients taking coxibs compared to subjects taking non-selective NSAIDs was observed, detailed analysis of the results confirmed doubts regarding the safety of coxibs in reference to their influence, not only on the mucous membrane of the alimentary tract, but also on the cardiovascular system (8,27-29). VIGOR reported an increased risk in the occurrence of cardiovascular events in the group of patients taking rofecoxib, which led to its recall by the Food and Drug Administration in December, 2004. In addition, previous studies have reported that celecoxib increased the incidence of cardiovascular complications compared to that of the placebo, but did not increase general mortality $(30,31)$. An explanation for the adverse events caused by COX-2 inhibitors was ascribed to the action of these drugs resulting in the decreased synthesis of $\mathrm{PGI}_{2}$, which reveals vasodilating and anti-aggregating properties previously known. In vivo, decreasing the synthesis of $\mathrm{PGI}_{2}$ may have been associated with superior influence of its functional antagonist, thromboxane $(7,32)$.

While the safety of coxibs, which in the light of previous data confirming increased cardiovascular risks may raise doubts, the vasodilating action of celecoxib itself is well-documented. Animal studies on guinea pigs and rats reported that celecoxib dilated coronary arteries in guinea pigs and large arteries in rats by intensifying the effects of NO/cGMP associated with the inhibition of PDE5 (33). In these studies, the vasodilating efficacy of celecoxib was found to be reduced compared to that of sildenafil, but higher compared to that of zaprinast. It was also reported that the vasodilating efficacy of celecoxib was limited by the NO synthase inhibitor (L-NAME) and guanylyl cyclase inhibitor. In direct measurements, celecoxib increased the levels of cGMP in the smooth muscle treated with sodium nitroprusside at a concentration of $5 \times 10^{-7} \mathrm{M} / \mathrm{L}$ by $\sim 5$-fold. These unexpected actions of celecoxib were explained with PDE5 block, which significantly compensated for the decrease of cAMP associated with the assumed reduction in $\mathrm{PGI}_{2}$ synthesis. $\mathrm{EC}_{50}$ of celecoxib was also established in relation to human $\mathrm{PDE}_{\mathrm{A} 1}$ at $1.6 \times 10^{-5} \mathrm{M} / \mathrm{L}$.
Previous studies have reported that the use of celecoxib is associated with a reduced risk in developing or losing control of hypertension, as well as with a reduced risk of acute cardiovascular events, than it is with selective COX-2 inhibitors, in particular, rofecoxib $(31,34,35)$. It was suggested that celecoxib may reduce endothelial dysfunction $(16,36,37)$. Studies using recombinant human $\mathrm{PDE}$ have indicated that celecoxib also inhibited the activity of PDE4 $\left(E_{50}=1 \times 10^{-5} \mathrm{M} / \mathrm{L}\right)$, but did not influence PDE1, 2 and 3. It was emphasized that the effects of low intracellular concentrations of $\mathrm{PGI}_{2}$-dependent cAMP caused by celecoxib may be compensated by increased cGMP, inhibition of PDE3 by cGMP and by the direct inhibition effects of celecoxib on PDE4 (33). These properties have not been confirmed on other selective COX-2 inhibitors except for valdecoxib, which may inhibit PDE5, but more weakly compared to that of celecoxib (2). It is vital that the vasodilating properties of celecoxib were also observed in vivo. An increase in blood flow in the brachial artery was identified in patients with hypertension following treatment with celecoxib in a placebo-controlled trial (38). This supports the hypothesis that celecoxib restores endogenous vasorelaxing sensitivity.

Recently, it was reported that selective COX-2 inhibitors restored, not only the vasodilating response of sclerotically degenerated arteries, but also the vasoconstricting response. Experimental data provided by studies evaluating sclerotically degenerated arteries in rabbits suggested an increased sensitivity to noradrenalin to the level comparable to the sensitivity of normal arteries following the use of indomethacin. Lowered $\mathrm{PGI}_{2}$ synthesis was observed under the influence of the COX-2 inhibitor, but this decrease was only associated with sclerotically degenerated arteries (39). These data confirm previous in vivo observations regarding COX-2 inhibitors, which may clearly influence the vascular system not only by limiting the synthesis of $\mathrm{PGI}_{2}$ and $\mathrm{TXA}_{2}$ (which appears the most distinct), but also by increasing the sensitivity to vasodilating as well as vasoconstricting factors. In conclusion, the present study identified high vasorelaxing efficacy of celecoxib at the background of the PDE inhibitors, which was observed not only in the presence, but also in the absence of the endothelium and may be evidence for relaxation caused by this COX-2 inhibitor in the cAMP- and cGMP-dependent pathways.

\section{References}

1. Grześk G, Koziński M, Navarese EP, Krzyżanowski M, Grześk E, Kubica A, Siller-Matula JM, Castriota F and Kubica J: Ticagrelor, but not clopidogrel and prasugrel, prevents ADP-induced vascular smooth muscle cell contraction: a placebo-controlled study in rats. Thrombos Res 130: 65-69, 2012.

2. Rajakariar R, Yaqoob MM and Gilroy WD: COX-2 in inflammation and resolution. Mol Interv 6: 199-207, 2006.

3. Smyth EM and FitzGerald GA: Prostaglandin mediators. In Handbook of Cell Signaling. Bradshaw RA and Dennis EA (eds). Second Edition Academic Press, San Diego, pp265-273, 2003.

4. Bresalier RS, Sandler RS, Quan H, Bolognese JA, Oxenius B, Horgan K, Lines C, Riddell R, Morton D, Lanas A, Konstam MA and Baron JA: Cardiovascular events associated with rofecoxib in a colorectal adenoma chemoprevention trial. N Engl J Med 352: 1092-1102, 2005.

5. FitzGerald GA: Coxibs and cardiovascular disease. N Engl J Med 351: 1709-1711, 2004.

6. Nussmeier NA, Whelton AA and Brown NT: Complications of the COX-2 inhibitors parecoxib and waldecoxib after cardiac surgery. N Engl J Med 352: 1081-1091, 2005. 
7. Solomon SD, McMurray JJV, Pfeffer MA, Wittes J, Fowler R, Finn P, Anderson WF, Zauber A, Hawk E and Bertagnolli M; Adenoma prevention with celecoxib (APC) study investigators: Cardiovascular risk associated with celecoxib in a clinical trial for colorectal adenoma prevention. N Engl J Med 352: 1071-1080, 2005.

8. Bavry AA, Khaliq A, Gong Y, Handberg EM, Cooper-Dehoff RM and Pepine CJ: Harmful effects of NSAIDs among patients with hypertension and coronary artery disease. Am J Med 124: 614-620, 2011.

9. Bertagnolli MM, Hsu M, Hawk ET, Eagle CJ and Zauber AG: Statin use and colorectal adenoma risk: results from the adenoma prevention with celecoxib trial. Cancer Prev Res 3: 588-596, 2010.

10. Koller A, Sun D, Huang A and Kaley G: Corelease of nitric oxide and prostaglandins mediates flow-dependent dilation of rat gracilis muscle arterioles. Am J Physiol 267: H326-H332, 1994.

11. Ganesan AN, Maack C, Johns DC, Sidor A and O'Rourke B: Beta-adrenergic stimulation of L-type $\mathrm{Ca}^{2+}$ channels in cardiac myocytes requires the distal carboxyl terminus of $\alpha_{1 \mathrm{C}}$ but not serine 1928. Circ Res 98: e11-e18, 2006.

12. Keef KD, Hume JR and Zhong J: Regulation of cardiac and smooth muscle $\mathrm{Ca}^{2+}$ channels $(\mathrm{CaV} 1.2 \mathrm{a}, \mathrm{b})$ by protein kinases. Am J Physiol Cell Physiol 281: C1743-C1756, 2001.

13. Kilic A, Bubikat A, Gassner B, Baba HA and Kuhn M: Local actions of atrial natriuretic peptide counteract angiotensin II stimulated cardiac remodeling. Endocrinology 148: 4162-4169, 2007.

14. Münzel T, Feil R, Mülsch A, Lohmann SM, Hofmann F and Walter U: Physiology and pathophysiology of vascular signaling controlled by cyclic guanosine 3 ',5'-cyclic monophosphate-dependent protein kinase. Circulation 108: 2172-2183, 2003 .

15. Rybalkin SD, Yan C, Bornfeldt KE and Beavo JA: Cyclic GMP phosphodiesterases and regulation of smooth muscle function. Circ Res 93: 280-291, 2003.

16. Zaccolo M and Movsesian MA: cAMP and cGMP signaling cross-talk: role of phosphodiesterases and implications for cardiac pathophysiology. Circ Res 100: 1569-1578, 2007.

17. Bender AT and Beavo JA: Cyclic nucleotide phosphodiesterases: molecular regulation to clinical use. Pharmacol Rev 58: 488-520, 2006.

18. Somlyo AP and Somlyo AV: $\mathrm{Ca}^{2+}$ sensitivity of smooth muscle and nonmuscle myosin II: modulated by $\mathrm{G}$ proteins, kinases, and myosin phosphatase. Physiol Rev 83: 1325-1358, 2003.

19. Oberwittler H, Hirschfeld-Warneken A, Wesch R, Willerich H, Teichert L, Heinz KH, Lehr E, Ding R, Haefeli WE and Mikus G: Significant pharmacokinetic and pharmacodynamic interaction of warfarin with the NO-independent sGC activator HMR1766. J Clin Pharmacol 47: 70-77, 2007.

20. Yetik-Anacak G, Xia T, Dimitropoulou C, Venema RC and Catravas JD: Effects of hsp90 binding inhibitors on sGC-mediated vascular relaxation. Am J Physiol Heart Circ Physiol 291: H260-H268, 2006.

21. Herrera M and Garvin JL: Novel role of AQP-1 in NO-dependent vasorelaxation. Am J Physiol Renal Physiol 292: F1443-F1451, 2007.

22. Tanaka K and Koyama Y: Endothelins decrease the expression of aquaporins and plasma membrane water permeability in cultured rat astrocytes. J Neurosci Res 89: 320-328, 2011.

23. Slupski M, Szadujkis-Szadurski L, Grzesk G, Szadujkis-Szadurski R, Szadujkis-Szadurska K, Wlodarczyk Z, Masztalerz M, Piotrowiak I and Jasiński M: Guanylate cyclase activators influence reactivity of human mesenteric superior arteries retrieved and preserved in the same conditions as transplanted kidneys. Transplant Proc 39: 1350-1353, 2007.
24. Chenevard R, Hurlimann D, Bechir M, Enseleit F, Spieker L, Hermann M and Riesen W: Selective COX-2 inhibition improves endothelial function in coronary artery disease. Circulation 107: 405-409, 2003

25. Simionescu M: Implications of early structural-functional changes in the endothelium for vascular disease. Arterioscler Thromb Vasc Biol 27: 266-274, 2007.

26. Foudi N, Kotelevets L, Louedec L, Leseche G, Henin D, Chastre E and Norel X: Vasorelaxation induced by prostaglandin E(2) in human pulmonary vein: role of the EP(4) receptor subtype. Br J Pharmacol 154: 1631-1639, 2008.

27. Grosser T, Fries S and FitzGerald GA: Biological basis for the cardiovascular consequences of COX-2 inhibition: therapeutic challenges and opportunities. J Clin Invest 116: 4-15, 2006

28. Mamdani M, Juurlink DN, Lee DS, Rochon PA, Kopp A, Naglie G Austin PC, Laupacis A and Stukel TA: Cyclooxygenase-2 inhibitors versus non-selective non-steroidal anti-inflammatory drugs and congestive heart failure outcomes in elderly patients: a population-based cohort study. Lancet 363: 1751-1756, 2004.

29. Wolfe F, Zhao S and Pettitt D: Blood pressure destabilization and edema among 8538 users of celecoxib, rofecoxib, and nonselective nonsteroidal antiinflammatory drugs (NSAID) and nonusers of NSAID receiving ordinary clinical care. J Rheumatol 31: 1143-1151, 2004.

30. Aw TJ, Haas SJ, Liew D and Krum H: Meta-analysis of cyclooxygenase-2 inhibitors and their effects on blood pressure. Arch Intern Med 165: 490-496, 2005.

31. Brinker A, Goldkind L, Bonnel R and Beitz J: Spontaneous reports of hypertension leading to hospitalisation in association with rofecoxib, celecoxib, nabumetone and oxaprozin. Drugs Aging 21: 479-484, 2004.

32. Cheng Y, Austin SC, Rocca B, Koller BH, Coffman TM, Grosser T, Lawson JA and FitzGerald GA: Role of prostacyclin in the cardiovascular response to thromboxane A2. Science 296: 539-541, 2002.

33. Klein T, Eltze M, Grebe T, Hatzelmann A and Kömhoff M: Celecoxib dilates guinea-pig coronaries and rat aortic rings and amplifies NO/cGMP signaling by PDE5 inhibition. Cardiovasc Res 75: 390-397, 2007.

34. Francois H, Athirakul K, Howell D, Dash R, Mao L, Kim HS, Rockman HA Fitzgerald GA, Koller BH and Coffman TM: Prostacyclin protects against elevated blood pressure and cardiac fibrosis. Cell Metab 2: 201-207, 2005.

35. Gudbjornsson B, Thorsteinsson SB, Sigvaldason $\mathrm{H}$, Einarsdottir R, Johannsson M, Zoega H, Halldorsson M and Thorgeirsson G: Rofecoxib, but not celecoxib, increases the risk of thromboembolic cardiovascular events in young adults - a nationwide registry-based study. Eur J Clin Pharmacol 66: 619-625, 2010

36. Akiko H, Kazunao K, Kazuhiko T, Naoki I, Kazuo U, Kyoichi O and Hiroshi W: Cyclooxygenase-dependent vasoconstricting factor(s) in remodelled rat femoral arteries. Cardiovasc Res 79: $161-168,2008$

37. Flórez A, de Haro J, Martínez E, Varela C, Bleda S and Acín F: Selective cyclooxygenase-2 inhibition reduces endothelial dysfunction and improves inflammatory status in patients with intermittent claudication. Rev Esp Cardiol 62: 851-857, 2009.

38. Widlansky ME, Price DT, Gokce N, Eberhardt RT, Duffy SJ, Holbrook M, Maxwell C, Palmisano J, Keaney JF Jr, Morrow JD and Vita JA: Short- and long-term COX-2 inhibition reverses endothelial dysfunction in patients with hypertension. Hypertension 42: 310-315, 2003.

39. Foudi N, Norel X, Rienzo M, Louedec L, Brink C, Michel JB and Back M: Altered reactivity to norepinephrine through COX-2 induction by vascular injury in hypercholesterolemic rabbits. Am J Physiol Heart Circ Physiol 297: H1882-H1888, 2009. 